\title{
Etiologia do senso comum: as Lesões por Esforços Repetitivos na visão dos portadores
}

\author{
Andréia de Conto Garbin, Ilidio Roda Neves e Regina Maria Batista
}

\section{Resumo}

Tendo em vista a importância das representações populares para a compreensão de aspectos psicossociais do processo saúde-doença e o grande desafio que as Lesões por Esforços Repetitivos (LER) têm colocado aos profissionais de saúde, esta pesquisa teve como objetivo investigar e descrever as concepções de trabalhadores portadores de LER a respeito da doença, procurando analisar as implicações para suas vidas e para as relações que estabelecem com outros atores sociais. As explicações encontradas podem ser classificadas em individuais, laborais e extra-laborais.

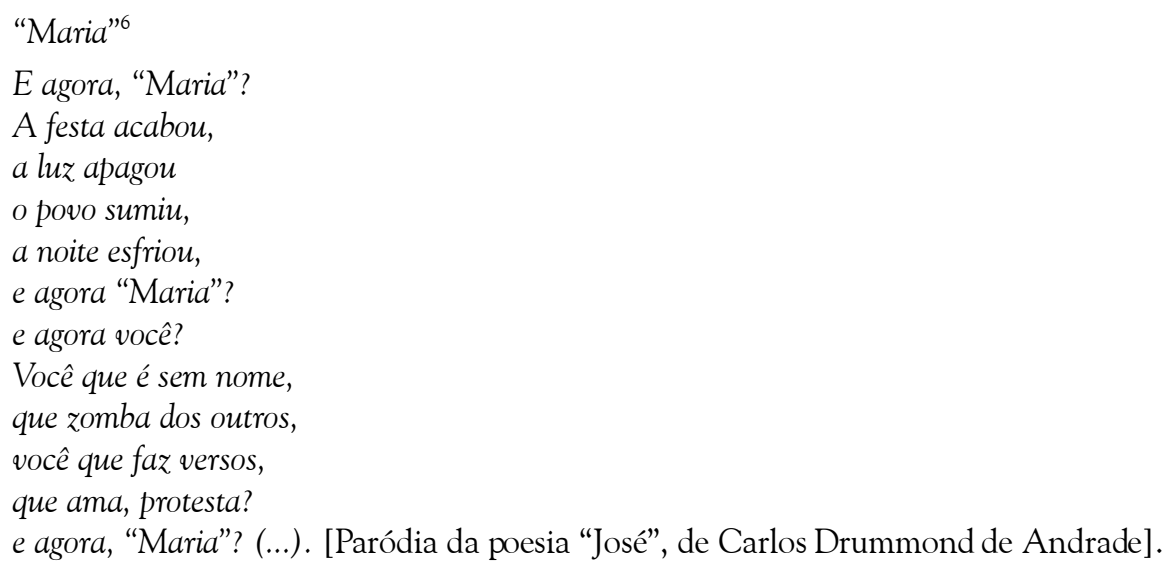

\section{Introdução}

Vivemos em nossa sociedade intensas mudanças nas relações de trabalho e nas formas de produção. $\mathrm{O}$ modelo organizacional de tradição taylorista-fordista tem se mantido paralelo a novas formas de organização do trabalho no interior do sistema produtivo que respondem às necessidades de uma economia cada vez mais competitiva. Como conseqüência, temos o aumento dos casos de doenças relacionadas ao acelerado ritmo de trabalho, automatização das linhas de montagem e reestruturação produtiva. Dentre estas doenças encontramos as Lesões por Esforços Repetitivos (LER)?

Vários países viveram verdadeiras epidemias de LER (Austrália, Japão, Inglaterra, Estados Unidos, só para citar alguns). No Brasil, os primeiros trabalhos sobre

5 Supervisores: Fábio de Oliveira e Lúcia Fonseca de Toledo. Também participaram desta pesquisa as alunas Ana Lúcia Gondim Bastos e Cybelle T. Al-Assal. Os dois primeiros autores são psicólogos do Centro de Referência em Saúde do Trabalhador de São Paulo. Regina Maria Batista é aluna de pós-graduação em psicologia social do Instituto de Psicologia.

6 Utilizamos um trecho e alteramos o nome original da poesia "José" para "Maria”, em homenagem à maioria de nossos entrevistados: as mulheres.

7 Esta denominação está sendo alterada para Distúrbios Osteomusculares Relacionados ao Trabalho (DORT) pela Previdência Social, na proposta de atualização da Norma Técnica sobre LER (Diário Oficial da União de 11 de Julho de 1997 , edital n 1 de 9 de Julho de 1997). Para as finalidades deste artigo, mantivemos a denominação corrente. 
o assunto foram escritos já na década de 70. Em 1982, o sindicato representante dos trabalhadores da área de processamento de dados do Rio Grande do Sul detectou um grande número de casos de trabalhadores que apresentavam dores nos membros superiores. A doença foi chamada inicialmente de "doença dos digitadores" (Assunção e Rocha, 1993).

Como observado em outros países, no Brasil a doença também revela um caráter epidêmico, atingindo diversas categorias profissionais e não apenas os digitadores. Assim, em meados da década de 90, passa-se a adotar a denominação Lesões por Esforços Repetitivos.

As Lesões por Esforços Repetitivos consistem em uma síndrome do sistema músculo-esquelético caracterizada por dor crônica, acompanhada ou não por alterações observáveis e se manifesta principalmente nos membros superiores em decorrência da sua maior utilização no trabalho fabril.

De acordo com a Norma Técnica do INSS, que regulamenta o diagnóstico da doença, as LER são definidas como:

Afecções que podem acometer tendões, sinóvias, músculos, nervos, fáscias, ligamentos, isolada ou associadamente, com ou sem degeneração de tecidos, atingindo principalmente, porém não somente, os membros superiores, região escapular e pescoço, de origem ocupacional, decorrente, de forma combinada ou não, de:

a) uso repetido de grupos musculares;

b) uso forçado de grupos musculares e

c) manutenção de postura inadequada.

O diagnóstico da LER é essencialmente clínico e baseia-se na história clínicoocupacional, no exame físico detalhado, nos exames complementares, quando justificados, e na análise das condições de trabalho responsáveis pelo aparecimento da lesão.

Os sintomas mais comuns das LER, segundo Settimi e Silvestre (1995), são: perda da força nos membros superiores; dores constantes; parestesia, sensação de pontada, agulhada, dormência, ardor, fraqueza, peso, fadiga e queimação; sensação de frio nos membros superiores, mais especificamente em mãos e dedos; sensação de inchaço nos membros superiores e ombros; sensação de enrijecimento muscular; sensação de cãibras e vários graus de distúrbios do sono e repercussões psicológicas.

Dentre as incapacidades decorrentes das LER, as autoras citam a diminuição da agilidade dos dedos, sentidas principalmente na digitação e na escrita; dificuldade para pegar, segurar, manusear pequenos objetos, como lápis, talheres e abotoar roupas; dificuldade para manter os membros superiores elevados, como nos movimentos para estender roupas no varal, segurar apoio em ônibus ou metrô, pentear cabelos; sensação de peso para carregar bolsa a tiracolo, sacolas e também bebês. 
As LER são patologias que se instalam insidiosamente em determinados segmentos do corpo em conseqüência do trabalho que exige movimentos repetitivos, esforços excessivos e posturas inadequadas. A doença atinge trabalhadores de diversos ramos de atividade: metalúrgico, eletroeletrônico, bancário, comercial, de confecção etc.

Diversas são as dificuldades desencadeadas pelas LER na vida dos trabalhadores: dor, limitações físicas, perda de capacidade para o trabalho, desrespeito e desconfiança por parte da maioria dos empregadores, menosprezo e humilhação observados na relação com médicos peritos do INSS, incompreensão da família, desestruturação da identidade, dentre outras tantas situações.

Entendemos que as LER - como as outras doenças - são construções sociais, isto é, os significados a ela atribuídos são oriundos dos processos sociais de construção de sentido. Não conhecemos sua natureza de imediato, assim, tanto a medicina quanto o senso comum constroem teorias e representações para interpretar e compreender o fenômeno. O objetivo desta pesquisa é conhecer como os portadores de LER representam, significam e explicam essa patologia. Buscaremos, desta forma, compreender as teorias do senso comum construídas pela população estudada para dar conta deste aspecto difícil de suas vidas.

De acordo com Minayo (1988), a opção por aprofundar a compreensão da causação das doenças na visão popular justifica-se pelo fato de que essas explicações traduzem muitas atitudes e práticas dos grupos populacionais relativos ao processo saúde-doença. Ainda, a autora aponta a oposição entre medicina (saber científico) e o senso comum (saber popular), reconhecendo um conflito entre estes dois saberes. Para analisarmos o discurso produzido pelo portador de LER, partiremos das explicações do senso comum confrontando-as com o conhecimento científico. Consideramos esses dois saberes como estruturas diferentes e inter-relacionadas, que não fazem parte de uma hierarquia na qual uma encontra-se submetida à outra. São considerados aqui como construções distintas que trazem em seu bojo aspectos importantes para a compreensão do sentido que as pessoas, em sua vida cotidiana, constroem para a doença e seu processo de adoecimento.

Spink, citando Jodelet (1984), nos relata que:

...os processos de conhecimento e de representação (...) estão relacionados à interação dinâmica de elementos sociais e culturais que formam o universo de referência, o escoramento a partir do qual os sujeitos sociais vão construir suas teorias e suas experiências (Spink, 1994: p. 37).

As teorias e representações sobre as LER, adotadas pelos portadores, têm suas origens na cultura popular, na experiência de vida no local de trabalho, no contato com profissionais de saúde e outros espaços de sociabilidade, nos quais concepções de mundo podem ser intersubjetivamente construídas. Essas concepções têm implicações cruciais na adesão dos pacientes aos tratamentos oferecidos pelos serviços de saúde; na atitude dos portadores diante da doença, dos médicos e das desconfianças advindas de seu ambiente social; nas possíveis ações reivindicatórias a serem levadas a cabo pelo coletivo dos trabalhadores.

Nossa opção pela noção de representação social para entender a maneira pela qual os indivíduos interpretam o mundo à sua volta, deve-se ao entendimento de que: 
...a representação é uma construção do sujeito enquanto sujeito social. Sujeito que não é apenas produto de determinações sociais nem produtor independente, pois que as representações são sempre construções contextualizadas, resultados das condições em que surgem e circulam. É, ainda uma expressão da realidade intra-individual, uma exteriorização do afeto (Spink, 1993: p. 303).

Sendo as LER uma doença que se encontra ainda em "construção" - isto é, não foi totalmente compreendida, não é amplamente conhecida pela população em geral e ainda não firmou seu espaço no imaginário social - a descrição e a compreensão das teorias e representações adotadas pelos seus portadores podem ser de grande importância na luta contra esse mal, pois, a partir delas, "desdobram-se o tratamento, as medidas preventivas e de recolocação dos portadores em atividades profissionais (recolocação profissional)" (Sato, 1993: p. 53). É justamente essa preocupação que define o objetivo principal desta pesquisa, que desta maneira apropria-se das LER como um objeto da psicologia social do trabalho.

\section{Metodologia}

Nesta pesquisa trabalhamos com portadores de LER que encontravam-se em tratamento no Centro de Referência em Saúde do Trabalhador do Estado de São Paulo (Cerest). Esse serviço caracteriza-se por atender um elevado número de portadores de LER e por desenvolver um programa especial de atendimento específico para a patologia. Dadas essas condições optamos por conduzir nossa pesquisa nesse serviço. A partir daí, nosso critério para a realização das entrevistas era que os pacientes tivessem seu diagnóstico clinicamente estabelecido ou, nos casos de primeira consulta, apresentassem os sintomas que caracterizam o quadro da doença e um histórico laboral compatível. Foram realizadas entrevistas com esses trabalhadores com o objetivo de captar as concepções, teorias e representações que possuem em relação à doença.

Estudamos dez casos de portadores de LER: a quase totalidade dos casos foi constituída por mulheres, com a exceção de um portador. Observamos que naquele serviço de saúde a maioria dos pacientes com o diagnóstico desta patologia é do sexo feminino. Esse dado também se verifica em outros serviços de saúde do trabalhador (Sato e cols., 1993).

Quanto ao setor de atividade, há, entre os casos estudados, o predomínio da área de serviços (7 pacientes são da área de serviços e 3 do setor industrial), esse predominância também é observada na população atendida pelo Cerest. As funções desempenhadas pelos trabalhadores são diversas: 2 caixas, 1 digitadora, 1 revisora de confecção, 1 auxiliar de coleta de sangue, 1 escriturária, 1 assistente administrativa, 1 auxiliar gráfica, 1 montadora de linha de montagem e 1 agente administrativa. Quanto à faixa etária, os portadores entrevistados tinham idades que variavam entre 25 e 50 anos.

Realizamos entrevistas abertas, que foram gravadas com o consentimento dos pacientes. Para tanto, elaboramos um roteiro que sistematizou a abordagem dos entrevistadores. 
Iniciávamos cada entrevista perguntando ao entrevistado sobre sua vida ou seu trabalho, com o objetivo de instaurar a situação de conversa entre o entrevistador e o entrevistado e trazer à consciência do entrevistado os conteúdos relacionados à sua vida, ao seu trabalho e às LER. Em seguida, a partir de uma pergunta norteadora: "Fale um pouco sobre as LER", o entrevistado passava a estruturar o campo discursivo, servindo as perguntas do entrevistador apenas para facilitar a expressão do entrevistado. Também elencamos algumas questões dirigidas para complementação do tema, caso não tivessem sido expressos até o final da entrevista: $\mathrm{O}$ que é LER? O que causa LER? Por que as pessoas têm LER? Como alguém sabe que tem LER? Que tipo de doença que é a LER?

Ao final da entrevista preenchíamos um questionário sociodemográfico com o objetivo de complementar as informações anteriores, traçando um perfil profissional e histórico das LER em cada caso estudado.

$\mathrm{Na}$ transcrição da entrevistas, reproduzimos o relato fidedigno dos entrevistados.

As entrevistas foram analisadas através da identificação de temas recorrentes apresentados nas várias falas dos trabalhadores. A análise do material colhido nas entrevistas serviu para "mapear o discurso a partir dos temas emergentes definidos a partir da leitura flutuante e guiado pelos objetivos da pesquisa” (Spink, 1994: p. 131).

\section{Resultados}

Mesmo partindo do princípio de que os pacientes já possuíam diagnósticos de LER estabelecidos, deparamo-nos com dois casos cujas investigações para estabelecer diagnóstico estavam em fase inicial, pois estavam realizando suas primeiras consultas no Cerest. Optamos por incluir esses pacientes no conjunto dos casos estudados, dada a riqueza de seus depoimentos.

A maioria dos trabalhadores, no momento da entrevista, estava afastada do trabalho ou desempregada, tendo sua doença comunicada ao INSS através da Comunicação de Acidente de Trabalho ${ }^{8}$ (CAT).

No que se refere ao tempo de trabalho na empresa e na função, há uma variação acentuada entre os entrevistados. O tempo mínimo de trabalho na empresa foi de três anos e o tempo mínimo de trabalho na função foi de quatro anos. Da mesma forma, há uma variação no tempo em que os sintomas se manifestaram e no tempo transcorrido até o estabelecimento do diagnóstico de LER.

Os pacientes chegam ao Cerest através da indicação de outros pacientes, colegas de trabalho e sindicatos. A maioria dos entrevistados já havia participado de alguma atividade do Programa de Tratamento e Reabilitação de LER do referido serviço. Esse programa inclui tratamentos em fisioterapia e psicologia, além das consultas médicas. Sob esse aspecto genérico do tratamento, também há uma trajetória de intervenções terapêuticas realizadas em outros locais, geralmente marcadas pela falta de atendimento adequado, seja na rede pública de saúde, seja na rede particular. Em muitas falas evidenciam-se semelhanças nas referências aos atendimentos obtidos no

8 De acordo com a legislação todas as doenças ou acidentes de trabalho devem ser notificados através deste documento. 
Cerest. São relatos nos quais os pacientes declaram ter recebido informações, esclarecimentos e tratamento satisfatórios.

A partir da leitura atenta das entrevistas procuramos conhecer como os portadores constroem suas teorias sobre a etiologia das LER. Deparamo-nos com a emergência de diversos temas a respeito da patologia que não estavam necessariamente relacionadas às causas. Através da identificação destes temas recorrentes, presentes nas várias falas dos trabalhadores, elencamos categorias para a análise dos discursos.

As categorias evidenciadas versavam sobre: que tipo de doença e o que são as LER, suas causas, formas de diagnóstico, seus sintomas, formas de tratamento e prevenção, as explicações da doença oferecida por outras pessoas e os discursos sobre as LER a que teve acesso, o descrédito em relação à veracidade da existência dos sintomas e as repercussões das LER nas vidas dos portadores. Dessa forma, analisando os dados obtidos deparamo-nos com explicações que abarcam desde o processo inicial do adoecimento até as medidas profiláticas adotadas.

A construção da doença como um objeto é um processo gradual. As LER inicialmente são identificadas pela dor intensa e persistente, diminuição da força, dormência, formigamento, inchaço na parte do corpo atingida. Esses sintomas não são relacionados inicialmente às atividades laborais. São entendidos como uma somatória das tarefas domésticas, do trabalho e do estudo. Outras vezes, com movimentos bruscos que ocasionais ou posturas inadequadas, como por exemplo, "dormir de mau jeito". O processo de diferenciação das primeiras explicações ocorre quando o repertório de justificativas para compreender a dor se esgota e persistem os sintomas:

Uma coisa que não sara, uma dor de cabeça triste passa, né. Isso aqui não. (Irene', 37 anos, assistente administrativa).

Segundo Grimberg (1991), os trabalhadores utilizam uma metodologia diagnóstica baseada em critérios de localização e intensidade dos sintomas. Verificamos essa mesma estratégia diagnóstica entre os portadores de LER entrevistados. Eles localizam a dor nos membros superiores, principalmente nas mãos e punhos, ombro e pescoço, traduzido a afecção de outras partes do corpo como resultado de uma "dor que caminha". Manifestam também a percepção da intensidade dos sintomas através da referência a uma dor constante. O diálogo com outras pessoas que conhecem a patologia confirma o diagnóstico.

...começa a doer o braço e não sarar, não melhorar com medicamentos. (Augusta, 40 anos, digitadora).

A mão era aquela agonia, a mão direita, mas a dor foi subindo nesse braço aqui, aí foi subindo, eu reclamava desse braço esquerdo. (Maria, 40 anos, escriturária).

O grupo social que pesquisamos recorre a diversas concepções sobre a etiologia das LER, integrando explicações de causação individual, laboral e extra-laboral. Esse aspecto de multiplicidade explicativa é destacado por Minayo (1988):

...a visão popular da etiologia das doenças não é monolítica (...) [as] "teorias populares" desenvolvem-se a partir da experiência da vida e se reorganizam

9 Os nomes utilizados após as falas são fictícios. Somente a idade e a profissão estão corretos. 
constantemente no contato com a prática, tanto da medicina "oficial" como de todos os sistemas alternativos (p. 364).

As explicações individuais compreendem descrições de predisposição, hereditariedade e modos de agir:

Eu acho que algumas pessoas... vem muito do metabolismo do indivíduo..., acho que seria uma predisposição do organismo (...) [Como seria essa predisposição?] Uma fraqueza do organismo, não sei, talvez relacionado com a alimentação, má alimentação, talvez maus hábitos de vida (...) uma predisposição do organismo talvez relacionada com uma fraqueza, não é fraqueza a palavra que eu queria falar é... uma deficiência, do próprio organismo, como tem pessoas que não enxergam bem, tem pessoas que têm problema no dente, então eu acho que a gente é problema dos nervos. (Maria, 40 anos, escriturária).

O componente laboral causador da doença é descrito através das funções exercidas no trabalho e da organização do trabalho:

Eu estou assim devido ao meu trabalho! Eu não fui procurar. Apareceu... Então eu não fujo (...) Eu fiquei assim. De onde que eu fiquei assim? Brincando é que não foi. [De trabalhar...]. De trabalhar. (Conceição, 43 anos, agente administrativa).

Do que eu conheço, é exatamente por esses esforços repetitivos (...) algumas dores que eu sentia eu levava em conta que era excesso da função. (Maria, 40 anos, escriturária).

Os afazeres domésticos e os demandados pela vida escolar, abarcam atividades extra-laborais que contribuem para o surgimento da doença e que constituem o terceiro grupo de explicações:

(...) eu era, sou dona de casa, na época eu tinha 2 filhinhas pequenas, não tinha muito tempo prá descansar (...) Eu, por exemplo, sempre fui, na minha casa eu fazia tudo, é: dona de casa, lavava, passava, nunca, assim, tive um programa de exercícios, um programa de relaxamento. Aliás, naquela época, também, a gente nem ouvia falar sobre isso, talvez seja isso uma "qualidade de vida" (...) (Augusta, 40 anos, digitadora).

As causas das LER são apresentadas principalmente por um discurso ambíguo que correlaciona aspectos individuais e laborais como determinantes da doença. Ao longo dos relatos os portadores explicitam discursos contraditórios.

Vejamos um exemplo. Augusta, no início da entrevista atribui as causas das LER a "aquela competitividade entre as pessoas, somada a essa sobrecarga de trabalho (...) e também os equipamentos". E a seguir acrescenta: "acho que seria uma predisposição do organismo". Por fim, ressalta: "tem hora que eu chego a pensar que é, eu falo, acho que é problema de cabeça" (40 anos, digitadora).

Portanto, os trabalhadores lançam mão de diferentes repertórios para explicar a doença, isto é, as relações sociais estabelecidas possibilitam que o indivíduo se aproprie de vários conhecimentos: científicos, culturais, sociais, religiosos, para manifestarem diferentes formas de compreensão da doença. Esse tipo de contradição já é apontado por Spink, quando afirma que "...ao aprofundarmos a análise do senso comum 
deparamo-nos não apenas com a lógica e com a coerência, mas também com a contradição" (1994: p. 123). A autora ressalta ainda que "...as representações sociais são elaboradas a partir de um campo socialmente estruturado". Assim, a análise dos discursos sobre as causas das LER permitiu-nos conhecer múltiplas explicações enunciadas para dar conta do complexo fenômeno do adoecimento. Os repertórios lingüísticos expostos pelos entrevistados são determinados pelo contexto social amplo e pelas suas inserções de grupos, classes etc. É no cotidiano, nas relações sociais, que se constroem as teorias e concepções que exprimem ambigüidades e contradições sobre o trabalho, a doença e os demais aspectos da vida.

Embora esteja disponível e presente em suas falas um repertório interpretativo baseado em explicações psicológicas, ele não é significativo para a experiência vivida dos portadores, embora tenham implicações importantes, como veremos adiante. Um exemplo da utilização desse tipo de explicação é-nos dado por Irene:

(...) claro que não é o meu caso, psicológico, eu jamais ia ficar: "- Ah! Eu tenho isso, não posso trabalhar porque tenho aquilo", mas acho que pode ser, como toda... Tem mulher que tem dor de cabeça todos os dias... é uma coisa psicológica, não pode ser? [E como uma pessoa teria esse "psicológico"?] É, de tanto ouvir falar. Acho que fica muito na cabeça. Não, não é psicológico. Psicológico é quando é uma coisa assintomática, quando você criou, agora quando você está com uma dor... (Irene, 37 anos, assistente administrativa).

As explicações que enunciam causas psíquicas podem levar os pacientes a sentirem culpa por adoecerem, como já apontaram Lima e Oliveira (1995). Evidenciamos que estas teorias são adotadas pelos portadores no processo inicial do adoecimento. Os pacientes entrevistados no Cerest já passaram, na sua maioria, por atividades terapêuticas periódicas e mantêm contatos com outros portadores de LER, portanto, já receberam informações acerca da doença, dos seus direitos e, em uma certa medida, abandonaram as explicações psicológicas.

Deve-se destacar um aspecto evidenciado no uso do termo "psicológico". Há três formas distintas de abordá-lo: a primeira, seria aquela em que o portador de LER adquire a doença por sugestão de outro, ou seja, de tanto ouvir alguém falar que está doente. Como explicita Irene na sua fala anteriormente destacada. Outra maneira de utilizar esse termo está relacionada às características peculiares da doença: a invisibilidade, os exames negativos (ultrassonografia, eletromiografia e radiografia) e a demora nos resultados do tratamento possibilitam que as LER sejam explicadas como uma invenção dos indivíduos:

...às vezes, tem médico que acha que é sistema nervoso abalado (...) É muito desacreditada a doença de LER, ninguém ainda acredita muito, eles acham mais que é falta de vontade de trabalhar, é bem por aí que eles vêem a coisa (...) Acho que tudo que eles não conseguem explicar, acho que eles acham que é problema de cabeça. Quando eles, acho que, não acreditam de tudo que você está mentindo, então eles acham que você, como disse a assistente social da minha firma, efeitos, efeitos não, sintomas psicossomáticos, você está insatisfeita consigo mesmo, com alguma coisa ou sei lá porque motivo começa a ter problemas, segundo ela, no corpo todo, mas o meu é só no braço, eu acho que é por isso. (Augusta, 40 anos, digitadora). 
Por fim, a expressão "psicológico" aparece para descrever os sentimentos desencadeados pela doença, ou seja, as repercussões psicológicas originadas a partir do adoecimento:

...não é que a LER ocasiona problema psicológico, é que aquilo que a LER te faz com que você deixe de fazer, te afeta. Por exemplo, eu tenho dificuldade de abrir garrafas de refrigerante, eu não consigo, não tenho força nos dedos assim para abrir, entende? Então isso me causa problema psicológico, por que eu falo: "- Pô, eu tô ficando incapaz". (Jonas, 43 anos, caixa de retaguarda).

Dentre as repercussões, encontramos desgaste físico e emocional conseqüente da busca de tratamento, o descrédito comumente vivenciado, sentimentos de impotência para realização de tarefas domésticas, falta de perspectivas futuras associada à perda da capacidade laboral e o questionamento da identidade. Essas descrições são encontradas na literatura sob a denominação de "aspectos psicossociais das LER" (Sato e cols., 1993; Lima e Oliveira, 1995). As repercussões da doença são enfaticamente relatadas, marcando fortemente os discursos encontrados nas entrevistas. Insônia, dificuldade de concentração, sentimentos de inutilidade, marginalização, depressão, irritabilidade, nervosismo, choro e tristeza freqüentes, são relatados como decorrentes do adoecimento:

...a LER é uma praga, que invade seu espaço, prejudica seu relacionamento, prejudica sua família, prejudica seu modo de pensar, suas atitudes, seu modo de encarar a vida, o mundo, você vê tudo negro, sem perspectiva, você perde forças, não força física, você perde outras forças que deve estar dentro de você, você fica frágil, você fica desrespeitada. (Maria, 40 anos, escriturária).

...quer dizer, você fazia tudo antigamente, quase nada te prejudicava, hoje em dia você se sente inútil. Porque você pensa em fazer alguma coisa, mas no fim não dá prá você fazer. Então é uma doença que prejudica muito, deixar você fazer... Sei lá, é assim a gente se sente inútil com essa doença (Paula, 49 anos, auxiliar de gráfica).

Os portadores de LER enfrentam uma via-crúcis a partir dos primeiros sintomas que implicam em várias consultas médicas, exames, afastamentos do trabalho, avaliações periciais do INSS que, juntamente com as limitações, dores constantes e incompreensão, desencadeiam sofrimento psíquico.

As explicações médicas são dominantes na caracterização das LER elaboradas pelos pacientes do Cerest. "O sistema biomédico que é dominante em nossa sociedade penetra em todas as áreas e em todos os grupos sociais, configurando-se, para cada um deles de forma específica". (Minayo, 1988: p. 377). A doença é descrita através das estruturas anatômicas lesionadas e do trabalho executado. São freqüentemente relacionadas à síndromes reumáticas e à descalcificação dos ossos. $\mathrm{O}$ diagnóstico, estabelecido através dos exames, é tido pelo portador como a comprovação do adoecimento.

Vai atingindo as partes onde tem tendões devido às funções que você faz. (Rosa, 35 anos, caixa). 
Acho que precisa de muito exame prá identificar. Os exames eu acho que também não, pelo menos pelo que eu tenho ouvido eles mesmos dizer, não são cem porcento seguros, então às vezes dá ainda por cima negativo os exames... (Augusta, 40 anos, digitadora).

Os entrevistados, ao descreverem sua postura, seu modo de agir no trabalho, seu relacionamento com chefias antes do adoecimento, enfatizam o "empenho", a "dedicação", a "responsabilidade", a "força de vontade", o "fazer tudo certo", como se essas atitudes representassem a postura que o trabalhador deve ter para obter ascensão profissional, garantir seu trabalho e, por conseqüência, obter melhor qualidade de vida. As LER aparecem como um obstáculo que atrapalha esse empenho individual na busca da estabilidade profissional. Como decorrência dessa percepção, a maior parte dos nossos entrevistados tentou evitar que se tornasse público no ambiente de trabalho seu adoecimento, buscando tratamentos e orientações em horários alternativos, como almoço, férias etc.

Essas atitudes podem ser consideradas como de submissão às exigências patronais. Estimula-se esse tipo de postura como forma de cooptação e exploração do trabalhador, visando maior produtividade. Ao manifestarem suas dores ou a necessidade de atendimento, portanto interferir na produtividade exigida, o trabalhador começa a ser motivo de chacotas, por vezes é transferido de setor etc. Essa lógica organizacional e o enfrentamento das adversidades decorrentes do adoecimento desencadeiam um questionamento maior sobre sua própria postura profissional e as condições de trabalho.

Uma característica comum que permeia os discursos dos trabalhadores é a indefinição quanto ao seu futuro profissional. As perspectivas de vida são alteradas, por um lado, em virtude do medo do desemprego, que se apresenta como o provável desfecho para sua situação. Por outro lado, suas perspectivas também são alteradas por verem depositada no perito do INSS a decisão quanto ao afastamento ou a volta ao trabalho. É na arbitrariedade dos peritos que os pacientes de LER têm a definição sobre seu futuro, portanto têm apenas uma pequena margem de controle sobre seu tratamento e sua reabilitação. Tudo isso é agravado ainda mais pela crise estrutural vivida por nossa sociedade hoje, a qual, inserida no processo de globalização da economia, observa a diminuição dos postos de trabalho, a extinção de funções, a implementação de sistemas automatizados, bem como as novas formas de organização do trabalho. A conjunção desses acontecimentos tornou as possibilidades de emprego cada vez mais remotas. Os portadores de LER, doença que também resulta das formas como o trabalho é organizado, vêem a ameaça do desemprego como iminente, pois são obrigados a retornar a um mercado de trabalho que os considera improdutivos.

Um aspecto a ser destacado é o de que, na maioria dos relatos, há entraves na relação entre o trabalhador adoentado e a empresa. Quanto menos a empresa orienta o trabalhador frente ao adoecimento, maior é a dificuldade para obtenção de informações satisfatórias e diagnósticos precisos, pois é na empresa que primeiramente o trabalhador busca orientações. Essas dificuldades iniciais muitas vezes se repetirão no decorrer do tratamento, tendo reflexos no momento da volta ao trabalho, isto é, maiores serão as dificuldades de negociação para mudança de função, pausas, diminuição do ritmo de produção, adequação do mobiliário, que são, por seu turno, algumas das freqüentes e prováveis alterações no ambiente de trabalho para que a doença não reapareça. 
As LER denunciam um contexto organizacional que estabelece tarefas padronizadas, movimentos pré-fixados, tarefas fragmentadas, individualismo, divisão burocrática do trabalho, separação entre concepção e execução, horas-extras excessivas, jornadas de trabalho ininterruptas, pressão por produção, risco iminente de demissão, dentre outras características do sistema de trabalho adotado pelas empresas. Tais concepções desconsideram a diversidade humana produzindo, indivíduos adoecidos. Algumas trabalhadoras entrevistadas descrevem o processo de trabalho:

Então, ah, "- não existe produção..." existe sim! Ele é obrigado, ele é crucificado pela aquela produção (...) já é um meio de pressionar a pessoa a dar mais cada dia (...) então, prá mim, aquela empresa é como se fosse minha mãe, eu achava que ela era, pensava tudo que ela fazia, ela fazia pro meu bem e eu dava o máximo de mim prá compensar isso daí e a satisfação que eu tinha, que quando eu tive esse problema (...) eu fiquei muito chateada que eu comecei a perceber que, falei puxa, acho que a empresa de repente não é mãe, eu acho que ela é madrasta... (Augusta, 40 anos, digitadora).

Era um ambiente pesado, sempre foi muito carregado (...) era produção, tinha aquele negócio de primeiro lugar, segundo (...) fui trabalhando mais, era telex, era ordem de pagamento, já era telex não escrito, foi modernização o telex, e eu produzia, eu produzia, em 86 eu comecei a ficar doente. Aí eu comecei com uma coisa que eu não sabia o que estava acontecendo comigo, e ai eu falei pro meu médico, olha está acontecendo alguma coisa que eu não estou me agüentando, eu, eu, sinto um cansaço, eu estou com um problema assim, que eu não lembro mais as agências que eu passei as ordens de pagamento. Eu me sentia muito cansada, mas nunca me dei conta de dor assim, eu sentia, eu sentia cansaço, eu não podia pegar um peso por menor que fosse que eu sentia cansaço. E as cadeiras eram de plástico, aqui não tem nenhuma delas, eram de plástico então você ficava assim no telex [mostra a postura corporal], sabe, então eu sentia cansaço, eu sentia um cansaço e daquele cansaço eu fui diminuindo no telex. (Maria, 40 anos, escriturária).

No entanto, o portador não estabelece $a$ priori uma relação de causalidade entre o processo de adoecimento e o contexto laboral, pois compreendem que as dores oriundas do trabalho são inerentes à própria atividade de trabalhar, independentemente do contexto e das condições. Essa concepção traduz um entendimento das condições de trabalho como naturais e imutáveis. O que implica numa aceitação passiva das condições dadas.

Por fim, reconhecer como naturais aspectos no contexto laboral que causam doenças e acidentes e entender as LER como causadas por fatores individuais desprovidos de influências sociais, econômicas e políticas, são atitudes que refletem concepções que enfatizam mais a mudança de comportamento do que modificações no ambiente e na organização do trabalho. Esse entendimento pode contribuir para reivindicações menos radicais do que as necessárias para a erradicação da doença e a sua prevenção.

Por outro lado, a pesquisa revelou o estigma que os trabalhadores lesionados carregam e que redunda em sofrimento psicossocial. Esse estigma de ser alguém improdutivo remete primordialmente à questão da cidadania, pois, para o modo de produção capitalista, estar doente significa justamente "não ser produtivo", isto é, significa não corresponder ao papel social atribuído àqueles que vendem sua força de 
trabalho, uma vez que a atividade laboral fornece a base para a valorização e o reconhecimento sociais. $\mathrm{O}$ trabalhador torna-se, então, um indivíduo à margem da sociedade, sofrendo um processo paulatino de exclusão.

E se você for procurar emprego com a mesma carteira [de trabalho], você não vai conseguir emprego, uma pessoa afastada mais de um ano é como se você tivesse na testa um carimbo "olha, tenho LER, se você me admitir vai ter problema, porque eu vou ter que me afastar da empresa". Então, ninguém pega, dai o que é que você faz? Faz uma carteira nova, que não tem carimbo ${ }^{10}$ e fala que perdeu a velha? Tudo bem, ai você entra. Mas você é obrigado na empresa, pelo menos nas que estive, assinalar ou fazer uma observação que você tem LER, e se você tá na empresa e aparece esse problema e a empresa descobre que você já teve pode te mandar embora sem direito nenhum, porque você negou. (Jonas, 43 anos, caixa de retaguarda).

\section{Conclusão}

Considerando que as lesões por esforços repetitivos são um problema de saúde pública que tem incipiente reconhecimento social, esta pesquisa procurou entender melhor o complexo fenômeno que produz alterações nas diversas esferas da vida dos indivíduos - pessoal, profissional, familiar, social - à luz da visão dos portadores quanto à causalidade dessa afecção. Evidenciamos que as explicações de causa individual provocam busca de modificações no próprio comportamento porque os pacientes culpabilizam-se pelo adoecimento. Quando os discursos correlacionam aspectos individuais e laborais, observamos maior adesão ao tratamento, na medida em que as informações ampliam o entendimento das causas e do desenvolvimento das lesões, ocorrendo a procura de respostas e soluções ao problema e possibilitando a busca por direitos de cidadania.

A premissa de que os indivíduos interpretam os discursos a que tiveram acesso, redefinindo sua realidade social, nos permite visualizar estratégias de intervenção no processo de educação e informação em saúde que baseadas na idéia da saúde-doença como uma construção social. Nesse sentido, entendemos o processo saúde-doença pelos seus determinantes sociais: condições de vida, trabalho, educação etc., a partir de um modelo de compreensão do processo saúde-doença que considera a variabilidade e a diversidade entre as pessoas.

As explicações encontradas nos discursos dos entrevistados transcendem a gênese da doença e enunciam os diversos aspectos do processo de adoecimento: sintomas, diagnóstico, tratamento e suas repercussões psicossociais. Evocam, desta forma, um panorama geral desta patologia, o que nos permitiu analisar outras dimensões dessa problemática.

Denotam um conhecimento para explicar o fenômeno que perpassa os aspectos do trabalho: ritmo, exigências de produção e de qualidade, dupla jornada de trabalho pelas mulheres e o modo individual de responder às exigências desse mercado de trabalho. São explicações contraditórias e ambíguas que atribuem a causa das LER

10 Toda vez que é emitida uma CAT por acidente de trabalho (trajeto, típico ou doença) efetua-se um registro na Carteira Profissional. Esta "marca" na história laboral dificulta a recolocação profissional, na medida em que o trabalhador sofre uma discriminação no processo de seleção. 
tanto aos aspectos individuais, quanto a aspectos laborais. A ênfase nos aspectos laborais promove uma adesão mais ativa aos tratamentos por parte do trabalhador, que busca informações e orientações para garantir seus direitos. Porém quando há uma ênfase nas explicações individuais, revelam-se discursos culpabilizantes, que orientam a ação na busca um tipo de intervenção baseada em mudanças de comportamentos e de atitudes.

\section{Bibliografia}

Assunção, A. A.; Rocha, L. E. (1993). Agora... até namorar fica difícil: uma história de lesões por esforços repetitivos. In: Buschinelli, J.T.; Rocha, L. E. e Rigotto, R. M. (orgs.) Isto é trabalho de gente? Vida, doença e trabalho no Brasil. Petrópolis, Vozes, capítulo 23, p. 461- 493.

Grimberg, M. (1988). La construcción social de la salud enfermedad em trabajadores de la industria grafica. Etnia, Alavarría, Buenos Aires, 33: 33-50.

Grimberg, M. (1991). Tradición obrera y "cultura somática" entre los "gráficos": el procesamiento colectivo de um saber sobre la relación trabajo-salud. Cuardernos Médico Sociales, 57: 55-63.

Instituto Nacional de Seguridade Social (1993). Normas técnicas para avaliação de incapacidade: Lesões por Esforços Repetitivos, Brasília: Ministério da Previdência Social.

Lima, A. B. e Oliveira, F. (1995). Abordagem Psicossocial da LER: Ideologia da Culpabilização e Grupos de Qualidade de Vida. In: W. Codo e M.C.C.G. Almeida (orgs.) Lesões por Esforços Repetitivos: diagnóstico, tratamento e prevenção - uma abordagem interdisciplinar. Petrópolis: Vozes, capítulo 6, p. 136 -159.

Minayo, M. C. S. (1988). Saúde-doença: uma concepção popular da etiologia. Cadernos de Saúde Pública, 4 (4): 356-362.

Pereira, A.; Rodrigues, L. I. e Sartori, A. (1996). Tempos Modernos. Revista Atenção, 2 (5): 28.

Ribeiro, H. P. (1994). Conversando sobre LER, São Paulo: Afubesp-Banespa.

Sato, L.; Araújo, M. D.; Franco, M. A. J. (1993). Atividade em Grupos com Portadores de LER e Achados sobre a Dimensão Psicossocial. Revista Brasileira de Saúde Ocupacional. 79 (21): 49-62.

Settimi, M. M. e Silvestre, M. P. (1995). Lesões por Esforços Repetitivos: um problema da sociedade brasileira. In: W. Codo e M.C.C.G. Almeida (org.) Lesões por Esforços Repetitivos: diagnóstico, tratamento e prevenção - uma abordagem interdisciplinar, Petrópolis: Vozes, capítulo 11, p. 321-355.

Spink, M.J.P. (1994). Desvendando as teorias implícitas: uma metodologia de análise das repesentações sociais. In: S. Jovchelovitch e P.A. Guareschi (Orgs.) Textos em representações sociais, Petrópolis: Vozes, p. 117-145.

Spink, M.J.P. (1993). O conceito de Representação Social na abordagem Psicossocial. Caderno de Saúde Pública, 9 (3): 300-308. 